INDO GLOBAL JOURNAL OF

PHARMACEUTICAL SCIENCES

ISSN 2249- 1023

\title{
Isolation and Characterization of Potential Biosurfactant Producing Bacterial Strain
}

\author{
Meenakshi Tiwary, AK Dubey \\ Division of Biotechnology, Netaji Subhas Institute of Technology, Sector-3, Dwarka, New Delhi-110078, India \\ Address for Correspondence: AK Dubey; adubey.nsit@gmail.com, tiwary.meenakshi@gmail.com
}

\begin{abstract}
Biosurfactants are surface-active molecules, having both hydrophobic and hydrophilic domains. They are molecules that are capable of lowering the surface tension and the interfacial tension of the growth medium. Biosurfactant could be a possible potential alternative of chemical surfactant due to their non- toxicity and degradibility in the environment. Biosurfactants are synthesized by a wide variety of microorganisms. Biosurfactants can enhance bioremediation of hydrophobic compounds present in environment by forming stable emulsions. Although biosurfactants have promising use in bioremediation processes, their industrial scale production is costly compared to chemical surfactant. In present study ten strains of bacteria have been isolated from soil samples collected from petrol-pumps in Delhi via enrichment method. These strains were screened for biosurfactant production by oil-displacement method and oil-emulsion method. Out of ten bacterial strains, one strain showed maximum oil displacement and oil emulsion. Identification of this particular strain was done by Biolog and was identified as Pseudomonas aeruginosa. The biosurfactant activity was compared with chemical surfactant SDS and tween 80. Effect of different carbon and nitrogen source was seen on production of biosurfactant. Various parameter; $\mathrm{pH}$, temperature, inoculums concentration and dextrose concentration were optimized by response surface methodology. Anti-microbial activity was checked against Staphylococcus aureus and Candida albicuns. The biosurfactant was found to be active against staphylococcus aureus. The biosurfactant produced by Pseudomonas aeruginosa was characterized by TLC and GCMS. () 2014 iGlobal Research and Publishing Foundation. All rights reserved.
\end{abstract}

Conference Proceedings: International Conference on Life Sciences, Informatics, Food and Environment; August 2930, 2014

Indo Global Journal of Pharmaceutical Sciences( ISSN 22491023 ; CODEN- IGJPAI; NLM ID: 101610675) indexed and abstracted in EMBASE(Elsevier), SCIRUS(Elsevier),CABI, CAB Abstracts, Chemical Abstract Services(CAS), American Chemical Society(ACS), Index Copernicus, EBSCO, DOAJ, Google Scholar and many more. For further details, visit 